\title{
REVIEW
}

\section{Uroguanylin: a new actor in the energy balance movie}

\author{
C Folgueira1,2,3, S Barja-Fernandez ${ }^{1,2}$, P Gonzalez-Saenz',2, V Pena-Leon 1,2, C Castelao1,2, M Ruiz-Piñon ${ }^{1,4}$, \\ F F Casanueva ${ }^{2,5}$, R Nogueiras ${ }^{2,3}$ and L M Seoane ${ }^{1,2}$
}

1Fisiopatología Endocrina, Instituto de Investigación Sanitaria de Santiago de Compostela (IDIS), Complejo Hospitalario Universitario de Santiago de Compostela (CHUS/SERGAS), Santiago de Compostela, Spain

${ }^{2}$ CIBER Fisiopatología Obesidad y Nutrición (CiberOBN), Instituto Salud Carlos III, Madrid, Spain

${ }^{3}$ Department of Physiology, CIMUS, USC, IDIS Santiago de Compostela, Santiago de Compostela, Spain

${ }^{4}$ Operative Dentistry and Endodontics, USC, Santiago de Compostela, Spain

5Laboratorio de Endocrinología Molecular y Celular, USC, Santiago de Compostela, Spain

Correspondence should be addressed to L M Seoane: luisamaria.seoane@usc.es or Luisa.Maria.Seoane.Camino@sergas.es

\begin{abstract}
Uroguanylin (UGN) is a potential target in the fight against obesity. The mature protein is released after enzymatic cleavage from its natural precursor, proUGN. UGN is mostly produced in the gut, and its production is regulated by nutritional status. However, UGN is also produced in other tissues such as the kidneys. In the past, UGN has been widely studied as a natriuretic peptide owing to its involvement in several different pathologies such as heart failure, cancer and gastrointestinal diseases. However, recent studies have suggested that UGN also acts as a regulator of body weight homeostasis because it modulates both food intake and energy expenditure. This ultimately results in a decrease in body weight. This action is mediated by the sympathetic nervous system. Future studies should be directed at the potential effects of UGN agonists in regulating body weight in human obesity.
\end{abstract}

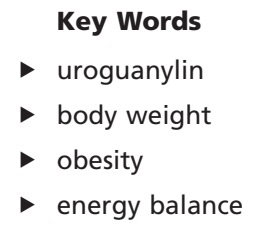

Journal of Molecular

Endocrinology

(2018) 60, R31-R38

\section{Introduction}

Energy homeostasis to maintain optimum body weight is implemented through the interaction between various neuroendocrine systems, and the gastrointestinal-brain axis has been revealed as a key mediator of this regulation (Cummings \& Overduin 2007). The gastrointestinal tract (GI tract) releases several peptides that act as hormonal and humoral signals-mainly in response to food intakewhich reach different regions of the brain and carry information about the nutritional status of the whole organism. Such signals can be translated into feelings of satiation or hunger to regulate appetite. Satiety signals are potential targets for the design of anti-obesity drugs, which would greatly advance the fight against obesity (Strader \& Woods 2005).
A recently discovered satiety peptidecalled uroguanylin (UGN) or GUCA2B (guanylate cyclase activator 2B) comprises 16 amino acids and is secreted as a prohormone (proUGN) from duodenal epithelial cells into the lumen. It undergoes postprandial enzymatic conversion into its active form. Once activated, UGN acts as an agonist of the transmembrane receptor guanylyl cyclase 2C (GUCY2C) on intestinal epithelial cells, increasing intracellular levels of cyclic guanosine monophosphate (cGMP) (Fruhbeck 2011, Valentino et al. 2011) (Fig. 1).

Guanylin or (GUCA2A, guanylate cyclase activator $2 \mathrm{~A}$ ) is an analog of UGN that also bind to the GUCY2C transmembrane receptor. It is a 15 -amino acid peptide that is secreted as a prohormone, proguanylin, from 


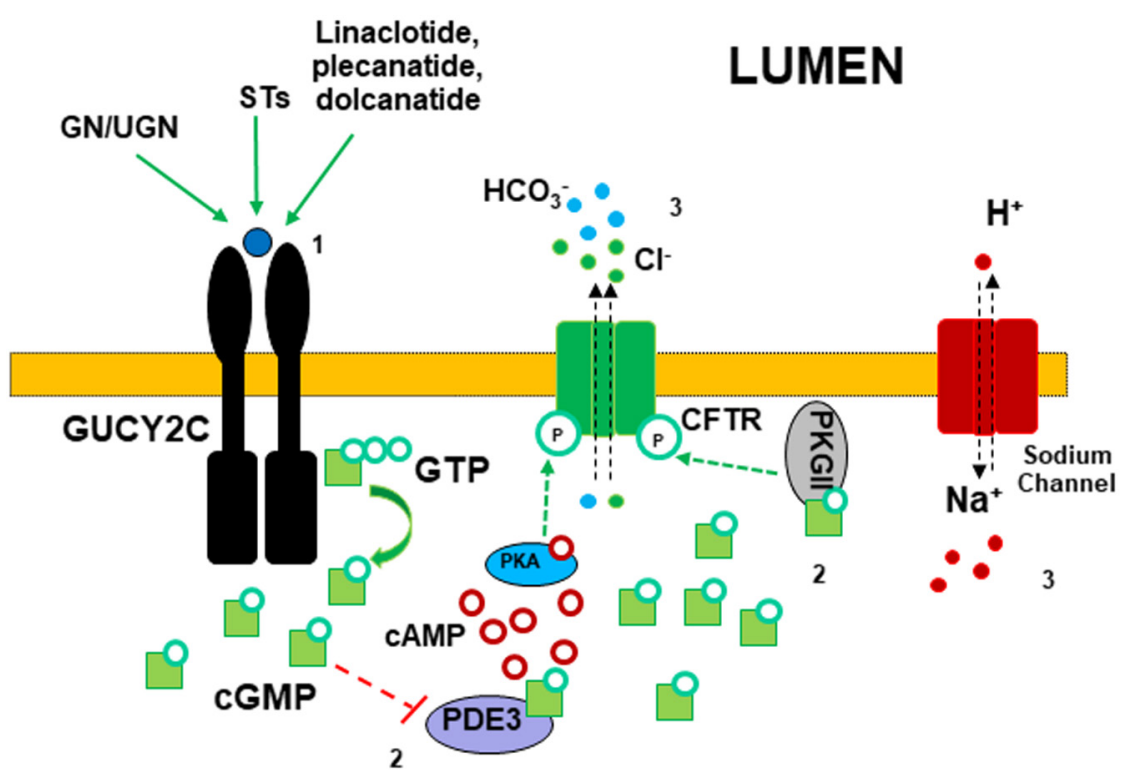

Figure 1

Mechanism of action of the GUCY2C-mediated signaling pathway. (1) Agonists of GUCY2C (guanylin (GN), uroguanylin (UGN), Staphylococcal enterotoxins (STs), linaclotide, plecanatide, and dolcanatide) activate the GUCY2C expressed on the apical surface of the cells, hydrolyze guanosine triphosphate (GTP), and increase the production of intracellular cyclic guanosine monophosphate (cGMP). (2) Elevated cGMP concentrations activate CGMP-dependent protein kinase, type 2 (PKG-II) and inhibit the activity of the CAMP-phosphodiesterase PDE3, thereby cross-activating CAMP-dependent protein kinase (PKA), leading to the phosphorylation and activation of the cystic fibrosis transmembrane conductance regulator (CFTR) ion channel, which stimulates the secretion of chloride $(\mathrm{Cl}-)$ and bicarbonate $\left(\mathrm{HCO}_{3}^{-}\right)$ions in the lumen. (3) The CFTR-mediated secretion of $\mathrm{Cl}^{-}$and $\mathrm{HCO}_{3}-$ ions is accompanied by the efflux of positive ions $\left(\mathrm{Na}^{+}\right.$ and $\mathrm{H}^{+}$), which follow the electronegative osmotic gradient. colonic epithelial cells and is cleaved into its active form (Schulz et al. 1990, Currie et al. 1992).

All GUCY2C analogs are responsible for decreasing sodium and water permeability, which increases chloride secretion owing to the phosphorylation of the cystic fibrosis transmembrane receptor (CFTR). This process is regulated by elevated levels of cGMP within epithelial intestinal cells. Overproduction of uroguanylin or guanylin leads to acute diarrhea, which is typically found in bacterial infections when Staphylococcal enterotoxins (STs) bind to the GUCY2C receptor (Currie et al. 1992, Forte \& Currie 1995).

Moreover, the pharmacological industry has created synthetic agonists of UGN that also bind to the GUCY2C receptor. Examples include linaclotide, which is used for the treatment of irritable bowel syndrome, retains many structural features of human bacterial enterotoxins (Brancale et al. 2017), and plecanatide and dolcanatide, which have many of the structural and functional characteristics of the endogenous ligand uroguanylin (Shailubhai et al. 2015).

\section{Regulation of intestinal UGN production}

The enterochromaffin cells (EC cells) of the intestine are the main source of UGN in humans and rats (Brenna et al. 2016). To a lesser extent, enteroendocrine cells (EE cells) are also a source of UGN. UGN is released from the gastrointestinal tract immediately after food intake (Valentino et al. 2011). Very prolific UGN mRNA expression in the small intestines of rats has been reported (Date et al. 1999), although lower levels have also been found in their stomachs (Folgueira et al. 2016b). Extraintestinal tissues such as the pancreas, adrenal glands, lungs and testis are also sources of UGN (Laney et al. 1992, Miyazato et al. 1996, Blanchard \& Cousins 1997, Li et al. 1997, Nakazato et al. 1998).

The intestinal levels of UGN are directly regulated by nutritional status and correlate with UGN levels in the plasma (Folgueira et al. 2016b). In mice, circulating levels of proUGN increase in response to the ingestion of nutrients (Valentino et al. 2011). According to the postprandial release of UGN, animals in a fasting state have reduced levels of UGN in the duodenum, which correlates with decreased plasma UGN levels, compared with animals fed ad libitum (Folgueira et al. 2016b). Furthermore, when fasted animals are re-fed, the intestinal and plasma levels of UGN are restored. These regulation of UGN by energy availability is dependent on leptin, an hormone synthesized and secreted in proportion to the amount of adipose tissue, whose levels are decreased in fasting states and restored after refeeding (Trayhurn et al. 1995). The following evidence supports this: first, UGN expression in the intestine was increased after intraperitoneal leptin injection at doses of $0.5 \mu \mathrm{g}$ per $\mathrm{g}$ body weight every $12 \mathrm{~h}$ for 3 days (Folgueira et al. 2016b). Second, in leptin-deficient $\mathrm{ob} / \mathrm{ob}$ mice, UGN levels remained unaltered after fasting or refeeding, indicating that nutritional status alone cannot regulate UGN production when leptin is not present (Folgueira et al. 2016b). Third, leptin-deficient ob/ob mice have low levels of intestinal and plasma UGN compared with their wild-type counterparts, and leptin treatment restores UGN levels in the ob/ob mutants to those found in the wild-type mice (Folgueira et al. 2016b). Finally, a 
classical model of hyperleptinemia (obese animals fed a high-fat diet) exhibits high levels of circulating leptin and increased levels of UGN in the intestine and plasma.

In addition, it has been suggested that a reduction in intestinal levels of UGN following intake of a high-calorie diet silences hypothalamic GUCY2C and regulates satiety. A novel mechanism has been proposed that involves a role for UGN in the disturbance of the gut-brain axis that occurs in obesity (Kim et al. 2016). However, GUCY2C receptors in the hypothalamus are not affected by obesity, which suggests that centrally administered UGN is effective in treating obesity. It is important to note that divergent circulating prouroguanylin levels have been found in human obesity compared to rodents with diet-induced obesity. In this sense, and accordingly to the findings in ob/ob mice, recent clinical studies have found decreased proUGN levels in both adolescent (Di Guglielmo et al. 2017a,b) and adult (Rodriguez et al. 2016) obese subjects. UGN downregulation in obesity is associated with endoplasmic reticulum (ER) stress (Kim et al. 2016). In line with this observation, a recent study
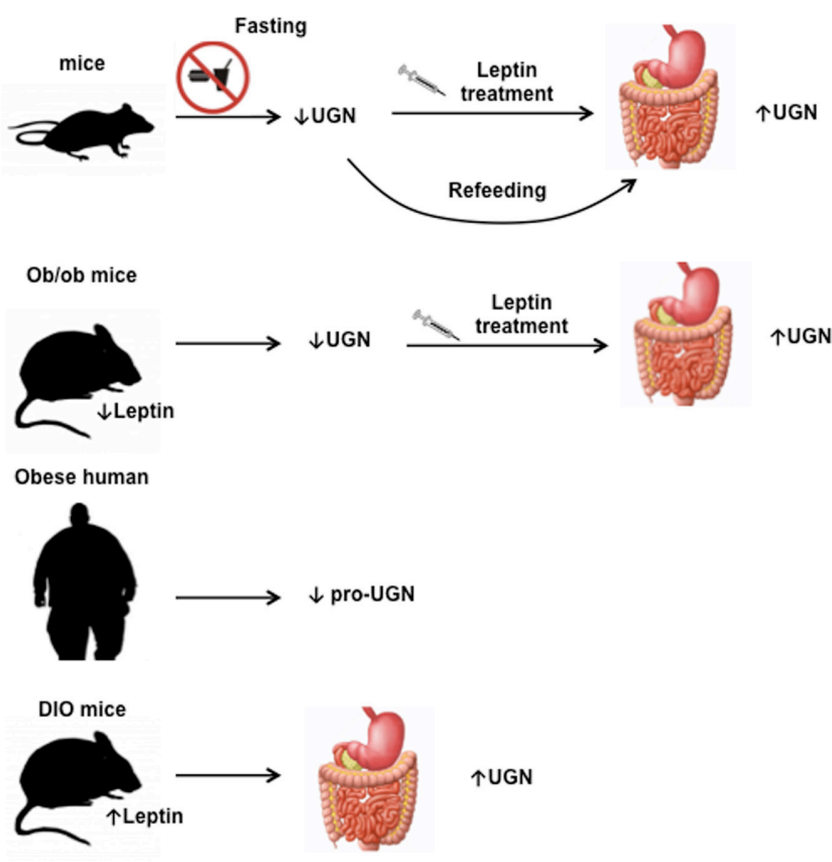

\section{Figure 2}

Regulation of intestinal uroguanylin (UGN) production by nutritional status is dependent of leptin levels. Food deprivation reduces UGN production in the duodenum, an effect that is reversed by the resumption of feeding or leptin treatment. Consistently, in an ob/ob mouse model of leptin deficiency, UGN expression is reduced in the duodenum and the levels revert after leptin treatment. Diet-induced obese mice with elevated levels of leptin exhibit increased UGN levels in the intestine compared with lean mice. has found that inflammation correlates with decreased circulating proUGN levels female adolescents with obesity (Di Guglielmo et al. 2017b). In addition, circulating proUGN levels are also decreased in human obesity in relation to adiposity, with weight loss achieved by bariatric surgery inducing a significant increase of circulating proUGN (Rodriguez et al. 2016).

In human obesity, the intestinal expression of guanylin peptides is not only regulated by leptin, but also by insulin and sexual hormones. In this regard, obese patient with type 2 diabetes exhibit increased protein expression of proguanylin in the small intestine compared with obese normoglycemic patients (Rodriguez et al. 2016). Moreover, female obese adolescents exhibit an increased intestinal immunostaining of uroguanylin and guanylin compared with age-matched male pairs (Di Guglielmo et al. 2017a).

In summary, nutritional status is a key factor in regulating UGN production, and leptin is a direct regulator of UGN production. Taken together, the evidence indicates that UGN is a part of the intestine-brain-adipose tissue network that regulates energy homeostasis and body weight (Fig. 2).

\section{Centrally administered UGN and energy homeostasis regulation}

It has been suggested that UGN plays a role as a satiety factor in the brain-gastrointestinal axis (Fruhbeck 2011) regulating food intake and energy homeostasis, and ultimately body weight. It is widely known that the integration of all neurohormonal signals produced in the periphery and the regulation of the appetite occur mainly in the hypothalamus. Accordingly, it has recently been discovered that once uroguanylin is secreted by the gut into the circulation, it targets the GUCY2C receptor of the hypothalamus, activating anorexigenic pathways and producing satiation in mice (Valentino et al. 2011).

\section{Pharmacological effects of acute UGN administration}

It has been shown that systemic administration of a GUCY2C agonist reduces food intake in wild-type mice, but this effect has not been observed in GUCY2Cdeficient mice. It has also been shown that GUCY2C activation in the central nervous system-especially in the hypothalamus - through the specific administration of a GUCY2C agonist reduces food intake (Valentino et al. 2011). In spite of these findings, reports assessing 
the metabolic role of endogenous UGN and its receptor have shown controversial findings. A study indicated that GUCY2C receptor knockout mice have elevated levels of body fat as a consequence of increased food intake (Valentino et al. 2011). In contrast, a following study showed that GUCY2C-knockout mice had unaltered body weight, adiposity and glucose tolerance (Begg et al. 2014). Therefore, the physiological significance of the UGNGUCY2C system for the control of energy homeostasis is not fully understood.

\section{Pharmacological effects of UGN chronically administered}

The putative anorectic action of UGN when administered at short term did not occur when UGN was administered for longer periods. The treatment of obese mice with centrally administered UGN during one week induces a reduction in body weight, independently of food intake (Folgueira et al. 2016a). The decrease in body weight found after UGN administration was accompanied by a reduction in body fat and was due to an increase in energy expenditure. Accordingly, the thermogenic program in brown adipose tissue (BAT) was activated as demonstrated by an increase in the main thermogenic markers (uncoupling protein 1 (UCP1), uncoupling protein 3 (UCP3), PR domain-containing 16 (PRMD16) and peroxisome proliferator-activated receptor gamma coactivator 1-alpha (PGC1- $\alpha$ ) in the BAT of UGN-treated obese mice (Folgueira et al. 2016a)). Furthermore, the central administration of UGN also induced the conversion of white adipocytes into brown adipocytes, a phenomenon named browning (Folgueira et al. 2016a). This was demonstrated by the increase in UCP-1 levels in the subcutaneous adipose tissue. In addition to this thermogenic effect, centrally administered UGN also stimulated lipid mobilization in subcutaneous adipose tissue indicated by the higher expression of pHSL (Folgueira et al. 2016a). Together, the different effects in white adipose tissue and BAT, which are mediated through the sympathetic nervous system, contribute to the reduction in body fat and body weight described in obese mice after treatment with centrally administered UGN. Besides the lipolytic action of uroguanylin through central mechanisms, the white adipose tissue expresses GUCY2C receptors and both guanylin and uroguanylin exert a direct action on human visceral adipocytes stimulating lipolysis through the activation and phosphorylation of HSL and the upregulation of several genes involved in lipid mobilization (Rodriguez et al. 2016).
Several studies have shown that $\beta$-adrenergic receptors constitute a key factor in the regulation of adipose tissue metabolism by the autonomous nervous system. Because the parasympathetic nervous system is not involved in the effect of centrally administered UGN at a peripheral level in adipose tissue, it is thought that the sympathetic nervous system plays a role. Accordingly, there is no effect following a central injection of UGN in the knockout mice for the three $\beta$-adrenergic receptors ( $\beta 1, \beta 2$ and $\beta 3$ ) with regard to body weight, fat mass or brown and white adipose tissue metabolism.

However, the effects of central UGN were not just limited to adipose tissue, because increased gastric motility was observed, as demonstrated by an increase in the amount of fecal matter. This gastric effect occurs via the vagus nerve, which is thought to be the main connection between the gastrointestinal tract and the brain (Seoane et al. 2007). Accordingly, the gastric effect of centrally administered UGN disappears in mice that have undergone surgical vagotomy. However, in such resected mice the effects of UGN on reducing body weight and fat mass, and increasing the thermogenic program and browning are still present, which suggests that these effects are the result of a mechanism that is independent of the parasympathetic nervous system (Folgueira et al. 2016a).

\section{Physiological role of UGN}

The physiological role of UGN in energy balance regulation is actually reinforced by the most recent published works. It was described that, centrally administered UGN induces weight loss and a reduction in fat mass in obese mice, independently of food intake. The effects of central UGN in peripheral organs are mediated by both branches of the autonomous nervous system, while the sympathetic nervous system controls fat metabolism in the adipose tissue and the parasympathetic nervous system regulates motility in the gastrointestinal tract (Fig. 3).

The effects of UGN on glucose homeostasis have not been fully elucidated. The only investigation of this aspect did not discover any effect of centrally administered UGN analogues on glucose homeostasis. In a study by Begg and coworkers (2014) UGN-deficient mice fed a high-fat diet did not show any alteration in glucose tolerance. However, when the mice were fed a mixed meal, they exhibited impaired glucose tolerance and elevated levels of glucose in the blood. Furthermore, the deficient mice also exhibited increased postprandial plasma insulin levels (Begg et al. 2014). In addition, it was recently described 


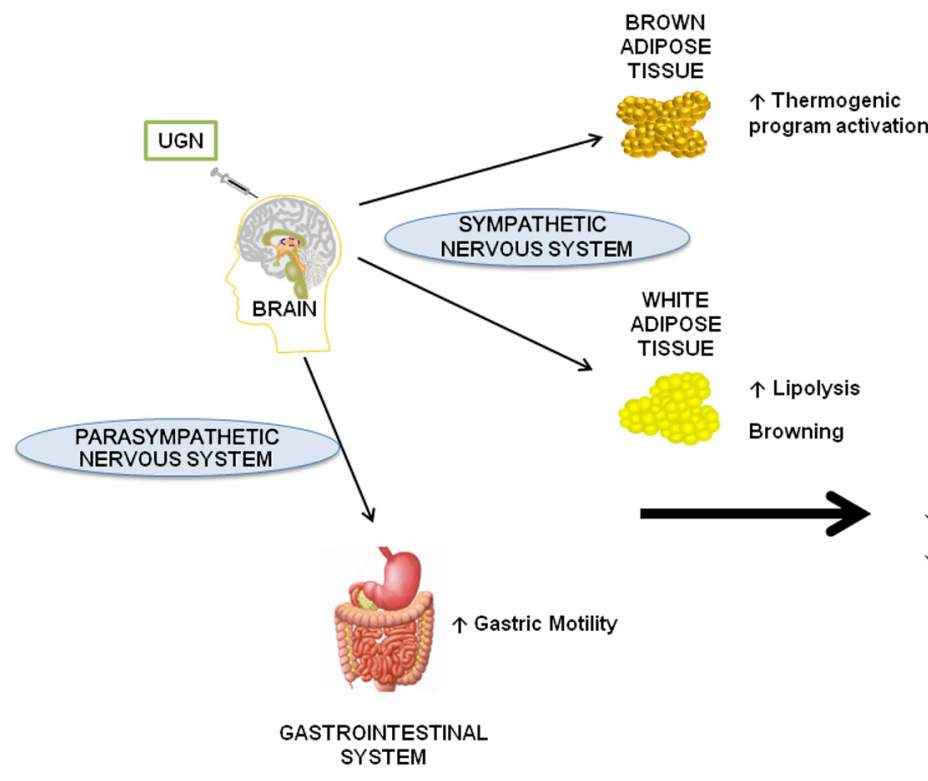

$\downarrow$ BODY WEIGHT $\downarrow$ ADIPOSITY

\begin{abstract}
Figure 3
Mechanism of central uroguanylin (UGN) action to reduce body weight and adiposity. The chronic central infusion of UGN reduces weight gain and adiposity in diet-induced obese mice, independently of food intake, and acts at different levels: centrally administered UGN induces brown adipose tissue thermogenesis, as well as browning and lipid mobilization in white adipose tissue through stimulation of the sympathetic nervous system. In contrast, brain UGN augments fecal output through the vagus nerve.
\end{abstract}

that circulating concentrations of proguanylin, but not prouroguanylin, are associated with markers of insulin resistance, such as glycemia or the HOMA index, and its intestinal protein expression is significantly increased in obese patients with type 2 diabetes (Rodriguez et al. 2016).

Future research should attempt to determine whether the loss of GUCY2C signaling is involved in the development of glucose intolerance and should elucidate the main mechanisms involved in glucose homeostasis due to UGN.

\section{Other functions of UGN}

Besides the emerging role of UGN in the gut-brain axis as a regulator of feeding, energy homeostasis, body mass and metabolism in rodents with normal physiology (Valentino et al. 2011, Folgueira et al. 2016a), other functions have been attributed to UGN-GUCY2C. These functions affect other physiological systems and are potential therapeutic targets in various pathologies including heart failure (HF), gastrointestinal diseases and cancer (Li et al. 2007, Lin et al. 2016).

It has been suggested that pro-uroguanylin (proUGN)-secreted from the intestine in response to oral salt loads - acts as an endocrine hormone on renal tubule epithelial cells as part of an entero-renal natriuretic axis (Forte et al. 1996). The infusion of both UGN and proUGN into rodents induces a natriuretic response activating the renal mechanisms involved in $\mathrm{Na}^{+}$excretion (Fellner et al. 2016). It was initially proposed that the dietary ingestion of salt induces an increase in the secretion of proUGN by EC (Moss et al. 2008). proUGN is converted to UGN in the intestine and the renal tubules (Hamra et al. 1996, Qian et al. 2008), leading to an increase of $\mathrm{Na}^{+}$in the urine (Greenberg et al. 1997, Nakazato et al. 1998, Lessa et al. 2012) and a decrease in intestinal $\mathrm{Na}^{+}$absorption (Joo et al. 1998, Toriano et al. 2011). As part of this entero-renal axis, UGN signaling acts by regulating $\mathrm{Na}^{+}$homeostasis. Salt ingestion is not reflected in circulating proUGN levels and does not affect the gastrointestinal expression of uroguanylin (Fellner et al. 2016), but high levels of salt intake induce the synthesis of proUGN in the kidney; proUGN is subsequently delivered to the lumen of the nephron in its active form, UGN. The most recent findings on this topic suggest that the regulation of the UGN system by salt consumption takes place mainly in the kidneys and is not related to the intestinal mechanism controlling UGN production (Toriano et al. 2011). The natriuretic effect of UGN has been described in UGN-knockout mice, which have hypertension as a consequence of a delay in sodium excretion (Fellner et al. 2016).

Patients that have experienced HF have high plasma levels of proUGN, and this alteration is initially showed to be independent of hypertension or renal alterations. Furthermore, UGN levels tend to increase as the severity of the HF increases (Carrithers et al. 2000). It is thought that the increase in UGN levels associated with HF might be due to impaired renal clearance leading to accumulation (Carrithers et al. 2000). Moreover, acute renal impairment increases the level of circulating proUGN and reduces its conversion into the active form. This is due to a decrease in glomerular filtration (Qian et al. 2008).

HF patients have a combination of impaired renal response and reduced renal clearance of circulating 
proUGN, resulting in diminished natriuretic and diuretic activity. The mentioned factors contribute to intravascular volume expansion, which explains the correlation between high prohormone levels and hypertension described, differently to that found by Carriethers and coworkers in a more recent study (Narayan et al. 2010).

The GUCY2C pathway is downregulated in patients suffering from chronic inflammatory bowel diseases (CIBD: Crohn's disease (CD) and ulcerative colitis (UC)); this downregulation is more significant when the clinical conditions worsen (Brenna et al. 2015). The GUCY2C signaling pathway plays a key role in the regulation of intestinal fluid and the balance of electrolytes. Guanylin and uroguanylin act by providing optimal intestinal mucosa hydration by secreting water, $\mathrm{NaCl}$, and $\mathrm{HCO}_{3}{ }^{-}$(Lan et al. 2016). In this context, it has been proposed that GUCY2C signaling regulates the intestinal inflammatory response. Accordingly, the restoration of the silenced pathway is a promising approach to treating patients with the chronic diseases mentioned earlier (Lan et al. 2016). Currently, various promising drugs that are structurally similar to uroguanylin and guanylin and act as potential therapeutic analogs are being tested to treat chronic diseases. Linaclotide is one such drug; it is used to treat CIBD and chronic idiopathic constipation (CIC) (Ahsan et al. 2017). Two other analogs of uroguanylin-plecanatide and dolcanatide-can be used to ameliorate colonic inflammation in acute and chronic models of murine colitis, possibly through the suppression of proinflammatory cytokine production (Shailubhai et al. 2015). Furthermore, recent clinical studies have confirmed that preparations of both drugs for oral administration are minimally absorbed into the systemic circulation and act locally in the gut lumen, eliminating the toxicity concerns associated with the existing systemic IBD therapies (Shailubhai et al. 2013).

Considering that the renewal process of the intestinal epithelium goes through a cycle of proliferation, migration, differentiation, apoptosis and ultimately loss of epithelial cells into the lumen, GUCY2C signaling is believed to be important in maintaining the balance between apoptosis and regeneration. Therefore, treatment with dolcanatide results in minimal loss of crypts and low distortion of crypt morphology, suggesting less infiltration of inflammatory cells (Shailubhai et al. 2015).

Finally, IBD patients are susceptible to cancer, so the therapeutic candidates described earlier could be useful for delaying disease progression. GUCY2C has been proposed as a tumor suppressor because it regulates the regenerative mechanism that maintains the integrity of the gut, which plays an essential role in the pathophysiology of colorectal cancer (Li et al. 2007). In obese mice, the loss of GUCY2C signaling is probably mediated by the activation of ER stress mechanisms induced by the consumption of excessive calories and the response of the unfolded protein (Lin et al. 2016).

In this context, one novel therapeutic approach to cancer prevention would be treatment with an oral preparation of linaclotide, a synthetic 14 -amino acid peptide that has more than $60 \%$ amino acid identity with guanylin and uroguanylin (Weinberg et al. 2017). A secondary therapeutic approach has been proposed that comprises the oral administration of plecanatide, which acts via cGMP/GC-C signaling to mediate the downregulation of Wnt/b-catenin signaling within the colon, thereby delaying the progression of colorectal cancer. Furthermore, recent clinical studies suggest that plecanatide is a safe and orally active drug candidate, with promising potential for use in the treatment of various GI disorders and diseases (Shailubhai et al. 2013).

These findings represent a new role for GC-C agonists in the chemoprevention of inflammation associated with colorectal carcinogenesis in populations at risk, including obese individuals.

\section{Concluding remarks}

The UGN-GUCY2C system constitutes a promising target in the fight against obesity. The pharmacological utility of GUCY2C agonist was suggested by the initial findings in preclinical models. The central administration of UGN to obese mice induce a decrease in body weight independent of food intake, an effect mediated by the increase in energy expenditure as probed by the activation of the thermogenic program in BAT and the induction of lipid oxidation in WAT. Futures studies should be aimed to elucidate if in humans the beneficial effects found in preclinical models are reproduced.

\section{Declaration of interest}

The authors declare that there is no conflict of interest that could be perceived as prejudicing the impartiality of this review.

\section{Funding}

This work was supported by the Instituto de Salud Carlos III (PI15/01272) and co-funded by FEDER. 


\section{References}

Ahsan MK, Tchernychev B, Kessler MM, Solinga RM, Arthur D, Linde CI, Silos-Santiago I, Hannig G \& Ameen NA 2017 Linaclotide activates guanylate cyclase-C/cGMP/protein kinase-II-dependent trafficking of CFTR in the intestine. Physiological Reports 5 e13299. (https://doi. org/10.14814/phy2.13299)

Begg DP, Steinbrecher KA, Mul JD, Chambers AP, Kohli R, Haller A, Cohen MB, Woods SC \& Seeley RJ 2014 Effect of guanylate cyclase-C activity on energy and glucose homeostasis. Diabetes 63 3798-3804. (https://doi.org/10.2337/db14-0160)

Blanchard RK \& Cousins RJ 1997 Upregulation of rat intestinal uroguanylin mRNA by dietary zinc restriction. American Journal of Physiology 272 G972-G978. (https://doi.org/10.1152/ ajpgi.1997.272.5.G972)

Brancale A, Shailubhai K, Ferla S, Ricci A, Bassetto M \& Jacob GS 2017 Therapeutically targeting guanylate cyclase-C: computational modeling of plecanatide, a uroguanylin analog. Pharmacology Research and Perspectives 5 e00295. (https://doi.org/10.1002/prp2.295)

Brenna O, Bruland T, Furnes MW, Granlund A, Drozdov I, Emgard J, Bronstad G, Kidd M, Sandvik AK \& Gustafsson BI 2015 The guanylate cyclase-C signaling pathway is down-regulated in inflammatory bowel disease. Scandinavian Journal of Gastroenterology 50 1241-1252. (https://doi.org/10.3109/00365521.2015.1038849)

Brenna O, Furnes MW, Munkvold B, Kidd M, Sandvik AK \& Gustafsson BI 2016 Cellular localization of guanylin and uroguanylin mRNAs in human and rat duodenal and colonic mucosa. Cell and Tissue Research 365 331-341. (https://doi. org/10.1007/s00441-016-2393-y)

Carrithers SL, Eber SL, Forte LR \& Greenberg RN 2000 Increased urinary excretion of uroguanylin in patients with congestive heart failure. American Journal of Physiology: Heart and Circulatory Physiology 278 H538-H547. (https://doi.org/10.1152/ajpheart.2000.278.2.H538)

Cummings DE \& Overduin J 2007 Gastrointestinal regulation of food intake. Journal of Clinical Investigation 117 13-23. (https://doi. org/10.1172/JCI30227)

Currie MG, Fok KF, Kato J, Moore RJ, Hamra FK, Duffin KL \& Smith CE 1992 Guanylin: an endogenous activator of intestinal guanylate cyclase. PNAS 89 947-951. (https://doi.org/10.1073/pnas.89.3.947)

Date Y, Nakazato M, Yamaguchi H, Kangawa K, Kinoshita Y, Chiba T, Ueta Y, Yamashita H \& Matsukura S 1999 Enterochromaffin-like cells, a cellular source of uroguanylin in rat stomach. Endocrinology 140 2398-2404. (https://doi.org/10.1210/endo.140.5.6734)

Di Guglielmo MD, Perdue L, Adeyemi A, van Golen KL \& Corao DU $2017 a$ Immunohistochemical staining for uroguanylin, a satiety hormone, is decreased in intestinal tissue specimens from female adolescents with obesity. Pediatric and Developmental Pathology. (https://doi.org/10.1177/1093526617722912)

Di Guglielmo MD, Tonb D, He Z, Adeyemi A \& van Golen KL 2017b A pilot study measuring the novel satiety hormone, pro-uroguanylin, in adolescents with and without obesity. Journal of Pediatric Gastroenterology and Nutrition Epub. (https://doi.org/10.1097/ MPG.0000000000001796)

Fellner RC, Moss NG \& Goy MF 2016 Dietary salt regulates uroguanylin expression and signaling activity in the kidney, but not in the intestine. Physiological Reports 4 e12782. (https://doi.org/10.14814/ phy2.12782)

Folgueira C, Beiroa D, Callon A, Al-Massadi O, Barja-Fernandez S, Senra A, Ferno J, Lopez M, Dieguez C, Casanueva FF, et al. 2016a Uroguanylin action in the brain reduces weight gain in obese mice via different efferent autonomic pathways. Diabetes 65 421-432. (https://doi.org/10.2337/db15-0889)

Folgueira C, Sanchez-Rebordelo E, Barja-Fernandez S, Leis R, Tovar S, Casanueva FF, Dieguez C, Nogueiras R \& Seoane LM $2016 b$ Uroguanylin levels in intestine and plasma are regulated by nutritional status in a leptin-dependent manner. European Journal of Nutrition 55 529-536. (https://doi.org/10.1007/s00394-015-0869-2)

Forte LR \& Currie MG 1995 Guanylin: a peptide regulator of epithelial transport. FASEB Journal 9 643-650.

Forte LR, Fan X \& Hamra FK 1996 Salt and water homeostasis: uroguanylin is a circulating peptide hormone with natriuretic activity. American Journal of Kidney Diseases 28 296-304. (https://doi. org/10.1016/S0272-6386(96)90318-2)

Fruhbeck G 2011 Gastrointestinal hormones: uroguanylin-a new gutderived weapon against obesity? Nature Reviews Endocrinology 8 5-6. (https://doi.org/10.1038/nrendo.2011.206)

Greenberg RN, Hill M, Crytzer J, Krause WJ, Eber SL, Hamra FK \& Forte LR 1997 Comparison of effects of uroguanylin, guanylin, and Escherichia coli heat-stable enterotoxin STa in mouse intestine and kidney: evidence that uroguanylin is an intestinal natriuretic hormone. Journal of Investigative Medicine 45 276-282.

Hamra FK, Fan X, Krause WJ, Freeman RH, Chin DT, Smith CE, Currie MG \& Forte LR 1996 Prouroguanylin and proguanylin: purification from colon, structure, and modulation of bioactivity by proteases. Endocrinology 137 257-265. (https://doi.org/10.1210/ endo.137.1.8536621)

Joo NS, London RM, Kim HD, Forte LR \& Clarke LL 1998 Regulation of intestinal $\mathrm{Cl}$ - and HCO3-secretion by uroguanylin. American Journal of Physiology 274 G633-G644.

Kim GW, Lin JE, Snook AE, Aing AS, Merlino DJ, Li P \& Waldman SA 2016 Calorie-induced ER stress suppresses uroguanylin satiety signaling in diet-induced obesity. Nutrition and Diabetes 6 e211. (https://doi.org/10.1038/nutd.2016.18)

Lan D, Niu J, Miao J, Dong X, Wang H, Yang G, Wang K \& Miao Y 2016 Expression of guanylate cyclase- $\mathrm{C}$, guanylin, and uroguanylin is downregulated proportionally to the ulcerative colitis disease activity index. Scientific Reports 6 25034. (https://doi.org/10.1038/srep25034)

Laney DW Jr, Mann EA, Dellon SC, Perkins DR, Giannella RA \& Cohen MB 1992 Novel sites for expression of an Escherichia coli heat-stable enterotoxin receptor in the developing rat. American Journal of Physiology 263 G816-G821. (https://doi.org/10.1152/ ajpgi.1992.263.5.G816)

Lessa LM, Carraro-Lacroix LR, Crajoinas RO, Bezerra CN, Dariolli R, Girardi AC, Fonteles MC \& Malnic G 2012 Mechanisms underlying the inhibitory effects of uroguanylin on NHE3 transport activity in renal proximal tubule. American Journal of Physiology: Renal Physiology 303 F1399-F1408. (https://doi.org/10.1152/ajprenal.00385.2011)

Li Z, Perkins AG, Peters MF, Campa MJ \& Goy MF 1997 Purification, cDNA sequence, and tissue distribution of rat uroguanylin. Regulatory Peptides 68 45-56. (https://doi.org/10.1016/S0167-0115(96)02103-9)

Li P, Schulz S, Bombonati A, Palazzo JP, Hyslop TM, Xu Y, Baran AA, Siracusa LD, Pitari GM \& Waldman SA 2007 Guanylyl cyclase C suppresses intestinal tumorigenesis by restricting proliferation and maintaining genomic integrity. Gastroenterology 133 599-607. (https://doi.org/10.1053/j.gastro.2007.05.052)

Lin JE, Colon-Gonzalez F, Blomain E, Kim GW, Aing A, Stoecker B, Rock J, Snook AE, Zhan T, Hyslop TM, et al. 2016 Obesity-induced colorectal cancer is driven by caloric silencing of the guanylinGUCY2C paracrine signaling axis. Cancer Research 76 339-346. (https://doi.org/10.1158/0008-5472.CAN-15-1467-T)

Miyazato M, Nakazato M, Matsukura S, Kangawa K \& Matsuo H 1996 Uroguanylin gene expression in the alimentary tract and extragastrointestinal tissues. FEBS Letters 398 170-174. (https://doi. org/10.1016/S0014-5793(96)01235-5)

Moss NG, Fellner RC, Qian X, Yu SJ, Li Z, Nakazato M \& Goy MF 2008 Uroguanylin, an intestinal natriuretic peptide, is delivered to the kidney as an unprocessed propeptide. Endocrinology 149 4486-4498. (https://doi.org/10.1210/en.2007-1725)

Nakazato M, Yamaguchi H, Date Y, Miyazato M, Kangawa K, Goy MF, Chino N \& Matsukura S 1998 Tissue distribution, cellular source, and structural analysis of rat immunoreactive uroguanylin. 
Endocrinology 139 5247-5254. (https://doi.org/10.1210/ endo.139.12.6347)

Narayan H, Mohammed N, Quinn PA, Squire IB, Davies JE \& Ng LL 2010 Activation of a novel natriuretic endocrine system in humans with heart failure. Clinical Science 118 367-374. (https://doi. org/10.1042/CS20090338)

Qian X, Moss NG, Fellner RC \& Goy MF 2008 Circulating prouroguanylin is processed to its active natriuretic form exclusively within the renal tubules. Endocrinology 149 4499-4509. (https://doi. org/10.1210/en.2007-1724)

Rodriguez A, Gomez-Ambrosi J, Catalan V, Ezquerro S, MendezGimenez L, Becerril S, Ibanez P, Vila N, Margall MA, Moncada R, et al. 2016 Guanylin and uroguanylin stimulate lipolysis in human visceral adipocytes. International Journal of Obesity $\mathbf{4 0}$ 1405-1415. (https://doi.org/10.1038/ijo.2016.66)

Schulz S, Green CK, Yuen PS \& Garbers DL 1990 Guanylyl cyclase is a heat-stable enterotoxin receptor. Cell 63 941-948. (https://doi. org/10.1016/0092-8674(90)90497-3)

Seoane LM, Al-Massadi O, Caminos JE, Tovar SA, Dieguez C \& Casanueva FF 2007 Sensory stimuli directly acting at the central nervous system regulate gastric ghrelin secretion. An ex vivo organ culture study. Endocrinology 148 3998-4006. (https://doi.org/10.1210/ en.2007-0226)

Shailubhai K, Comiskey S, Foss JA, Feng R, Barrow L, Comer GM \& Jacob GS 2013 Plecanatide, an oral guanylate cyclase C agonist acting locally in the gastrointestinal tract, is safe and well-tolerated in single doses. Digestive Diseases and Sciences 58 2580-2586. (https:// doi.org/10.1007/s10620-013-2684-z)
Shailubhai K, Palejwala V, Arjunan KP, Saykhedkar S, Nefsky B, Foss JA, Comiskey S, Jacob GS \& Plevy SE 2015 Plecanatide and dolcanatide, novel guanylate cyclase-C agonists, ameliorate gastrointestinal inflammation in experimental models of murine colitis. World Journal of Gastrointestinal Pharmacology and Therapeutics 6 213-222. (https://doi.org/10.4292/wjgpt.v6.i4.213)

Strader AD \& Woods SC 2005 Gastrointestinal hormones and food intake. Gastroenterology 128 175-191. (https://doi.org/10.1053/j. gastro.2004.10.043)

Toriano R, Ozu M, Politi MT, Dorr RA, Curto MA \& Capurro C 2011 Uroguanylin regulates net fluid secretion via the NHE2 isoform of the $\mathrm{Na} / \mathrm{H}+$ exchanger in an intestinal cellular model. Cellular Physiology and Biochemistry 28 733-742. (https://doi. org/10.1159/000335767)

Trayhurn P, Thomas ME, Duncan JS \& Rayner DV 1995 Effects of fasting and refeeding on ob gene expression in white adipose tissue of lean and obese (oblob) mice. FEBS Letters 368 488-490. (https://doi. org/10.1016/0014-5793(95)00719-P)

Valentino MA, Lin JE, Snook AE, Li P, Kim GW, Marszalowicz G, Magee MS, Hyslop T, Schulz S \& Waldman SA 2011 A uroguanylin-GUCY2C endocrine axis regulates feeding in mice. Journal of Clinical Investigation 121 3578-3588. (https://doi. org/10.1172/JCI57925)

Weinberg DS, Lin JE, Foster NR, Della'Zanna G, Umar A, Seisler D, Kraft WK, Kastenberg DM, Katz LC, Limburg PJ, et al. 2017 Bioactivity of oral linaclotide in human colorectum for cancer chemoprevention. Cancer Prevention Research 10 345-354. (https:// doi.org/10.1158/1940-6207.CAPR-16-0286)

Received in final form 28 November 2017

Accepted 4 December 2017

Accepted Preprint published online 4 December 2017 